\title{
The Rise and Fall of
}

\section{the Organizing Model}

\author{
in the U.S.
}

\author{
Richard W. Hurd \\ Professor of Labor Studies \\ Cornell University \\ (607) 255-2765 \\ rwh8@cornell.edu
}

\author{
forthcoming in \\ Trade Unions and Democracy:
}

Strategies and Perspectives

Edited by G. Wood and M. Harcourt

Manchester University Press 2004 


\section{With union representation at an all-time low and public support for unions the highest it's been in years, there's never been a better time for changing to organize.$$
\text { - AFL-CIO (1996:8) }
$$

Organizing has been at the center of union strategy discussions in the U.S. for twenty years, and since 1995 new member recruitment has been the top priority of the American Federation of Labor-Congress of Industrial Organizations (AFL-CIO) and of many individual national unions. Prompted originally by a steep drop in membership during the Ronald Reagan era, attention to organizing increased over time as it became clear that modest adjustments in practice were not halting decline. During the late 1980s an important step was taken with the founding of the Organizing Institute (OI), ostensibly a training school for organizers but symbolizing dreams for union revitalization.

In the 1990s impatience with continued stagnation grew among national union leaders, and John Sweeney was elected as President of the AFL-CIO on a platform that emphasized organizing. Sweeney had constructed labor's most successful recruitment program as the President of the Service Employees International Union (SEIU), and the hope was that he would be able to apply his magic touch to the labor movement as a whole. The enthusiasm and sense of movement inspired by Sweeney's election in 1995 served to magnify interest from abroad in the now clearly established organizing priority, especially among labor leaders and sympathetic academics in Great Britain, Australia, New Zealand and Germany where union fortunes were also in decline. The OI served as a prototype for Australia's Organizing Works and Britain's Organizing Academy. 
Much of the strategic debate in the U.S. has revolved around the organizing model, which is associated with more activist, grassroots methods of organizing and member mobilization. In spite of widespread endorsement of this model, the reality is that rhetoric has far outpaced action and mobilization is still a relatively isolated phenomenon. Furthermore, with only occasional pauses union density has continued its downward trend, especially in the private sector. This chapter reviews the evolution of recent union strategy in the U.S., with particular attention to organizational change initiated to promote the organizing priority. It also assesses the failure of organizing to halt contraction in spite of isolated successes, and evaluates future prospects.

\section{Historical Background}

Increased attention to organizing began a quarter of a century ago in the context of political defeat and economic dislocation. In 1978 a concerted labor law reform effort designed to facilitate recruitment failed in spite of Democratic Party control of both houses of Congress and support from President Jimmy Carter. The proposal was modest, increasing penalties for employer violations of the law and providing union staff with limited access to the workplace during recruitment campaigns. Nonetheless, passage would have facilitated growth without the need for organizational change; union organizers could have maintained their insurance agent posture and increased their sales activity, assured of adding new member-customers fully within the context of the (as yet unnamed) servicing model. Two years later President Carter's bid for re-election failed and the anti-union reign of Ronald Reagan began. 
The labor movement lost more than one-fifth of its private sector members during the first half of the 1980s. Although the President's appointees to the National Labor Relations Board issued a steady stream of adverse legal decisions, economic change proved far more devastating. Twin recessions in 1981 and 1983 were bad enough alone, but unions also faced the combined forces of globalization, deregulation (which started in the Carter years), and technological change. Manufacturing was hit particularly hard and leading unions like the United Steelworkers of America (USWA) and the United Automobile Workers (UAW) experienced sharp membership losses and dwindling resources. Concessionary bargaining began in manufacturing but quickly spread to other sectors. Unionized companies throughout the private economy began to turn to non-union contractors to perform work formerly assigned to their own employees.

It was in the context of this crisis that national union leaders confronted the deficiencies in prevailing union practice. The AFL-CIO Executive Council initiated strategic planning under the auspices of the newly created Evolution of Work Committee in 1983, with the presidents of the UAW, the USWA and most other top unions participating in the process. Initial consideration of dramatic restructuring of the labor movement through mega mergers to consolidate around "cones of influence" with clearly defined jurisdictions proved too threatening to some unions and the idea was abandoned. ${ }^{1}$ Instead, a blueprint for change was adopted in 1985 that included reorientation of the AFL-CIO as well as suggested courses of action for affiliated unions.

The strategic plan was summarized in The Changing Situation of Workers and Their Unions (AFL-CIO, 1985). Five sets of modest recommendations were included:

\footnotetext{
${ }^{1}$ Interestingly, this concept has resurfaced recently in the form of a framework proposed by the SEIU, as discussed in the final section of this chapter.
} 
- New methods of advancing interests of workers (including associate membership programs and union sponsored credit cards).

- Increasing members' participation in their union.

- Improving the labor movement's communications.

- Improving organizing activity.

- Structural changes to enhance the labor movement's overall effectiveness (including merger guidelines, a shadow of the cones of influence proposal).

The AFL-CIO's first major effort to promote organizing under the new plan was a coordinated campaign by nine different unions to recruit members at Blue Cross-Blue Shield, the largest provider of health insurance in the country. The experiment got off to an inauspicious start with a year's delay while the AFL-CIO first set up bureaucratic oversight of the effort then mediated competing union jurisdictional claims for different sub-units of the targeted company. By the time recruiting actually began, Blue CrossBlue Shield had implemented a union avoidance program and the response of workers was predictably cautious. There were a few isolated victories in small units, but the initiative ultimately failed and was abandoned (Northrup, 1990).

Although the AFL-CIO's attempt to broker a major organizing campaign was a disappointment, a small number of national unions took to heart the recommendations of The Changing Situation and implemented innovations in their own recruitment efforts. A theme issue of Labor Research Review (1986), aptly titled “Organize!", highlighted campaigns by SEIU, the Hotel Employees and Restaurant Employees (HERE), the Communications Workers of America (CWA), the International Brotherhood of Electrical Workers (IBEW), the American Federation of State, County and Municipal Employees (AFSCME), and the Amalgamated Clothing and Textile Workers (ACTWU, now part of UNITE, the Union of Needletrades and Industrial Textile Employees). These six national unions along with a few others subsequently have continued to lead the effort 
to establish an organizing priority. Given the decentralized structure of the U.S. labor movement, it is no accident that the AFL-CIO backed away from direct involvement in organizing after the Blue Cross-Blue Shield debacle and assumed a more supportive role. Supportive does not mean irrelevant, however, and the organizing model concept itself originated in two distinct initiatives sponsored by the federation.

\section{Emergence of the Organizing Model}

The original specification of the organizing model can be traced to a massive teleconference on "internal organizing" sponsored on February 29 and March 1, 1988, by the AFL-CIO and broadcast by satellite to multiple locations across the country with hundreds of elected leaders and union staff participating. In the U.S. internal organizing is used to refer to activity within unionized workplaces, and though some recruiting of non-members may result, the focus is on mobilizing current members for union action. The labor educators and organizers planning the conference decided to contrast the typical union workplace with an activist one using the terms servicing model and organizing model. As defined in Numbers That Count (Diamond, 1988), a training manual developed based on the teleconference, the servicing model is "trying to help people by solving problems for them," while the organizing model is "involving members in solutions." The idea is that unions can be more effective representing workers if they use the same mobilizing techniques with current members that are most effective when recruiting new members.

Throughout the late 1980's the organizing model was used almost exclusively to apply to internal organizing. The concept was refined based on practice as summarized in 
union oriented publications like the Labor Research Review. In an issue devoted to "Participating in Management," most of the discussion stressed strengthening the union by pushing joint labor management decisions down to the rank-and-file level. Internal organizing was emphasized (Banks and Metzgar, 1989:49):

The key component of the organizing model is its emphasis on mobilization of the rank and file to do the work of the union .... [which] gives members a sense of power as a group. When the members share in the decisions and all the activities of the union, they will also be sharing in the victories.

The concept was further refined, again based on practice, in another issue devoted exclusively to the topic, "An Organizing Model of Unionism" (Labor Research Review, 1991). Two of the articles reflect the theme: "Organizing Never Stops" (Muehlenkamp, 1991), and "Contract Servicing from an Organizing Model" (Conrow, 1991). Throughout this period, the discussion, writing and training on the organizing model concentrated on mobilization within existing units. There were reminders, though, of the close connection to recruitment, or "external organizing" as it is often called in the U.S. Morton Bahr, President of CWA, in a response to the discussion of participation in management, noted for example, "the mobilization model of participation is also the basis of CWA external organizing" (Bahr, 1989: 64).

The AFL-CIO's most influential recruitment initiative during this period was the formation in 1989 of the Organizing Institute (OI) to train union organizers. Headed by former ACTWU star organizer Richard Bensinger, the OI was established by the AFL$\mathrm{CIO}$ as an independent entity insulated from the bureaucratic culture of the tradition bound federation. It promoted an activist grassroots approach, and become something of an oasis for militant organizers from the dozen AFL-CIO affiliated unions with active 
recruitment programs. The OI developed a systematic process to train and place

organizers that it still follows today. Potential organizers are identified in local unions, on college campuses, and at social action organizations and invited to apply to the OI. Those who are accepted go through a three day training program on organizing methods, then are placed in three week internships with large scale organizing campaigns. If they perform well as interns they are offered six to twelve week apprenticeships sponsored by participating unions, then often move into staff jobs as organizers (Foerster, 2001: 161162).

By the mid 1990s the OI had trained and placed hundreds of organizers, and the style of member recruitment it promoted was accepted as the prevailing "model" of organizing. Perhaps because of the parallels to the mobilization approach to internal organizing outlined in Numbers that Count, it became common place for those in union circles to refer to the OI approach as the organizing model. Although the OI did not advocate this terminology, by 1995 the organizing model concept was indiscriminately used to refer to both internal organizing to mobilize members, and external organizing that promotes grassroots activism as a way to build support for union representation.

It is this merged conceptualization of the organizing model that has been exported from the U.S. to other labor movements (see for example: Carter and Cooper, 2002; Gall, 2003; Heery, 2001). The concept has been refined to incorporate academic research that lends credence to the effectiveness of recruitment strategies based on grassroots activism (e.g., Bronfenbrenner, et. al., 1998). As summarized by Heery, et. al. (2000:996):

... The 'organizing model ... tends to be used in two overlapping senses. First, it can refer to a model of good practice which contributes to membership growth ... Elements of this good practice include: reliance on targeted and planned organizing campaigns; ... identification 
of issues around which workers can be mobilized and the use of mobilizing tactics in the workplace ...; the use of rank-and-file' organizing committee's to plan and conduct campaigns... Second, it represents an attempt to rediscover the 'social movement' origins of labour, essentially by redefining the union as a mobilizing structure which seeks to stimulate activism among its members.

\section{Changing to Organize, Organizing for Change}

In spite of laudable efforts to promote mobilization and organizing, the U.S. labor movement continued to decline through the late 1980's and early 1990's. The pace of decline slowed as the economy recovered and the strategic response of labor took root, but there were no indications that widespread revitalization was close at hand. When the Republican right seized control of Congress in the November 1994 elections, a group of progressive national union leaders was spurred to action. It was their conviction that the AFL-CIO needed to adopt a more aggressive posture, and they turned to John Sweeney of SEIU a their standard bearer. Sweeney announced his candidacy for President of the AFL-CIO in the Spring of 1995; his "New Voice" slate also included Richard Trumka of the United Mine Workers and Linda Chavez-Thompson of AFSCME. Most of the national unions with active organizing programs supported Sweeney. The New Voice campaign was based on a series of proposals for change based on the premise that "the most critical challenge facing unions today is organizing," and they included a call to "organize at a pace and scale that is unprecedented" (Sweeney, Trumka and ChavezThompson, 1995:2,3). With organizing at the top of the agenda, the subsequent victory of Sweeney's slate was widely interpreted as an endorsement of this priority.

Once in office, the Sweeney team adopted a mission statement that specified four goals (AFL-CIO, 1997:1): 
- Building a broad movement of America's workers through organizing.

- Making government work for working families.

- Providing a new voice for workers in a changing global economy.

- Providing a new voice for workers in our communities.

The emphasis on recruitment was obvious as the new officers criss-crossed the country promoting the organizing priority. An Organizing Department was created (formerly recruitment was assigned to the Department of Field Services), and Richard Bensinger was appointed director. The OI was moved into the Organizing Department, its budget was increased sharply, and a new fund was established to subsidize strategic organizing campaigns.

In addition to overseeing the expansion of the OI and developing a process to select organizing campaigns worthy of subsidy, Bensinger was charged with redefining the federation's role in organizing. This was a daunting task because there was no tradition of leadership from the center in this arena. Apart from the Blue Cross-Blue Shield experiment, the AFL-CIO had restricted itself to supporting the recruitment efforts of affiliated unions, typically only in response to requests for assistance. The OI training program was far and away the most extensive undertaking in this field to date under the sponsorship of the federation.

With the endorsement of Sweeney and the other officers, Bensinger's Organizing Department set out to convince union leaders at the national and local level to embrace the organizing priority and to initiate institutional change to sustain increased organizing efforts. Bensinger worked closely with a group of union officials who had embraced the OI as participants in its elected leader task force. Bensinger kept the original OI group intact and added a few new members to form the AFL-CIO Elected Leader Task Force on 
Organizing, chaired by Bruce Raynor who at the time was Executive Vice President of UNITE (he has since been elected national President).

The Elected Leader Task Force held a series of retreats for union officials who expressed an interest in organizing, then late in 1996 released a blueprint titled, "Organizing for Change, Changing to Organize." The report called upon union leaders to take risks and make the dramatic changes necessary to succeed at organizing. It identified four keys to winning (Raynor, 1996: 13):

- Devote more resources to organizing.

- Develop a strong organizing staff.

- Devise and implement a strategic plan.

- Mobilize your membership around organizing.

This simple agenda but complex task dominated the work of the Organizing Department. The AFL-CIO officers were fully engaged, and shifting resources to support recruitment efforts quickly became the focal point of both their speeches and the Organizing Department's campaign. In consultation with Bensinger, Sweeney decided to operationalize the call to shift resources by asking all unions to move toward a goal of devoting $30 \%$ of their budgets to recruitment. To promote acceptance of the challenges associated with Changing to Organize the Organizing Department set as an objective for 1998 to: "lead an expanded Changing to Organize program and provide technical assistance to unions on crafting strategic plans to support a greatly increased organizing focus...," and to "help unions move the Changing to Organize message deeper and broader among local union leaders" (AFL-CIO, 1998:7).

Although the expanded OI training program continued to promote an activist approach tied to mobilization, it was in the late 1990s that strategic debates about 
recruitment moved away from the organizing model and began to concentrate on institutional structure and budgetary decisions. In order to understand the shift it is important to look at the barriers to organizational change that had stalled progress.

\section{Impediments to the Organizing Model and Organizational Change}

Back in the late 1980s and early 1990s the organizing model as originally conceived had attracted great attention throughout the U.S. labor movement. Numbers that Count was the most requested publication of the AFL-CIO. Many unions developed internal organizing initiatives. The CWA and SEIU, for example, had extensive union wide efforts, with the SEIU program stressing the connection between member mobilization and external organizing. However, implementation of the organizing model proved to be difficult except during the period immediately preceding the expiration of collective bargaining agreements (a time when member interest in local union affairs typically is at a peak no matter what model of unionism is practiced). It seems that at least in the U.S. members do not have a taste for continual warfare, preferring stability rather than on-going class struggle. Furthermore, mobilization does not free time for other pursuits; to the contrary, it requires careful planning and intense effort by staff and elected leaders in order to succeed. True, locals with effective internal organizing programs are vibrant, members are engaged, and effectiveness in the workplace improves. But this does not translate into growth because it concentrates attention on practice within existing units rather than outreach to potential new members (Fletcher and Hurd, 1998) 
This reality led labor leaders who embrace the organizing priority to refocus their efforts towards mobilization designed to support external organizing. As one unionist explains it (not coincidentally this individual is now the organizing director of a major union and a member of the AFL-CIO Elected Leader Task Force on Organizing): "The organizing model ... points us in the most narrow way. The better job you do with fifteen percent of the market, the more it motivates the boss to wipe you out. We have to direct our energy outside" (Fletcher and Hurd, 1998:45). It is this perspective that lies behind the AFL-CIO led campaign to persuade unions to shift resources away from representation and to concentrate instead on recruitment.

But adoption of the organizing priority is itself fraught with problems. Although mobilizing members in support of organizing is ostensibly an integral part of Changing to Organize, this component of the framework has been overshadowed with attention centered on building support among union leaders for a shift in resources. However, union members continue to demand representation. They are mostly pragmatists and it is difficult for them to accept the argument that devoting substantial resources to organizing will pay off eventually in the form of increased bargaining power and better contracts. Although those in the activist core often comprehend the basis for the emphasis devoted to recruitment, they nonetheless give most of their attention to representational functions.

In this context, union leaders at all levels are cautious. Even if they agree that recruitment is important they will pull back if they sense resistance from union members. This is especially a problem at the local level and in those instances where the leader has no personal expertise in organizing. Union staff also may be recalcitrant; though few will openly challenge leaders that promote organizing, those assigned to representation 
express pessimism and resent the increased workload that typically accompanies resource reallocation (Fletcher and Hurd, 2001).

The push for unions to reallocate resources to recruitment is far removed from the organizing model ideal of engaging workers in the life of the union. It appears that in many corners of the U.S. labor movement the objective of achieving grassroots activism and member mobilization as the key to injecting social movement zeal has been abandoned at the alter of quantitative recruitment goals. The ultimate limitation in the AFL-CIO's Changing to Organize is that it does not require organizational change beyond resource reallocation, but rather implies that union revitalization is simply a matter of adding members and spreading the labor movement as it exists. On the one hand this approach is pragmatic given the difficulty encountered sustaining the organizing model and the need for resources to construct an extensive recruitment effort. On the other hand it seems likely that without more substantive organizational change even the narrow goal of sustained membership growth will be difficult to achieve.

\section{Is Organizing Enough?}

In the summer of 1998 Richard Bensinger was asked by John Sweeney to step down as Organizing Director. His commitment to the organizing priority was unquestioned, but his frank criticism of national union leaders who did not demonstrate sufficient enthusiasm for the Changing to Organize agenda won few friends, and pressure mounted from members of the AFL-CIO Executive Council to have him replaced (Meyerson, 1998). In reality though the problem was not only with Bensinger, who had done a great deal to further the Sweeney goal of establishing organizing as the most 
important challenge facing unions. What Sweeney and his advisors had envisioned was re-positioning the federation so that it could assume a leadership role in organizing and other aspects of union strategy. But this dream of a stronger center building consensus around a common set of objectives was resisted on all sides by national union leaders with their own priorities.

After Bensinger's departure the AFL-CIO struggled to capture some semblance of authority in the organizing arena. In 2000 Sweeney was able to persuade the Executive Council to endorse a specific goal of organizing $1,000,000$ workers a year, and the federation's organizing program embraced a three-point process to achieve the objective (AFL-CIO, 2001:8):

- Encourage national affiliates to set and achieve higher numeric organizing goals.

- Assess how the federation's resources can best be used to help achieve these increased goals.

- Track and share information about organizing campaigns.

The $1,000,000$ goal was never taken seriously by affiliates, and the Organizing Department eventually has retreated to a more modest role comparable to the AFL-CIO's stance prior to Sweeney's election. The current practice is to provide assistance to national union organizing campaigns where possible, to continue to offer guidance to unions that agree to invest more resources into organizing, and to design a long term campaign to amend labor law to establish an enforceable right to organize unions (AFLCIO, 2002). Labor law reform is the most public part of the current effort and is referred to as the Voice@ Work campaign.

The reality is that individual national unions determine their own resource allocations and develop their own organizing programs. In response to Sweeney's 
prodding the leaders of the national unions have indeed accorded more importance to the recruitment priority, and virtually all lend at least rhetorical support. Most unions have increased the funding of their organizing departments, and many have devoted substantial resources to the effort. However, the individual unions jealously guard their authority over organizing strategy, staffing, target selection and all decisions related to coordination with other unions. The federation's role as arbiter of disputes where there is competition between unions in specific recruitment campaigns is accepted, but efforts by the AFL-CIO to broker broader agreements regarding organizing jurisdiction have been rejected.

National unions have followed the AFL-CIO's lead in establishing specific targets for budget reallocation and recruitment, though few have embraced the $30 \%$ guideline for budgets or the recruitment objectives implied by the $1,000,000$ new members a year benchmark. The individual unions' adoption of the practice of setting quantitative goals has forced them to act pragmatically, looking for organizing opportunities with the best chance of success. Although this often has meant seeking out workers who fit the culture and traditional industrial and/or occupational base of the union, many have seized the moment and taken steps to extend their jurisdictional boundaries. It is not unusual for them to conduct recruitment campaigns among workers in totally unrelated industries simply because there is a good chance of success. For example the UAW now has a very active program to recruit teaching assistants, research assistants and adjunct faculty on college campuses, and the USWA is organizing healthcare workers. In fact, there are at least a dozen unions organizing in healthcare, some with a long history in the industry but 
others like USWA with only indirect connections or no rationale other than capitalizing on the opportunity to add members.

A number of unions have implemented extensive and strategically focused programs, most notably the SEIU and the United Brotherhood of Carpenters (UBC) both of whom now allocate $50 \%$ of their national budgets to organizing. UNITE and HERE have comparable levels of commitment to the priority, and all four of these unions have accomplished the transition to organizing by strengthening the role of the national union and mandating change at the local level. Other unions (for example, CWA and IBEW) have adopted a different approach with some success, with the national union supporting and facilitating change at the local level but with less centralized control of the mechanics of the organizing itself (Hurd, 2001). Variation in the locus of control is only one of many differences in approach to organizing. With national unions operating independently and making pragmatic decisions about recruitment, it is not surprising that there is a wide range of opinions. As activity has increased these differences have spawned open debate about all aspects of organizing. The earlier apparent consensus regarding the organizing model and the grassroots approach to recruitment has long since dissolved. In the context of quantitative goals, the ideal of organizing as a method of engaging members and building commitment has given way to debates about how to be cost effective and manage recruitment programs efficiently.

The lack of consensus about organizing strategy has come to the surface because union density has continued to decline in the U.S. This is in spite of nearly a decade under the leadership of John Sweeney and in spite of broad endorsement for the organizing priority. Tables 1 and 2 summarize the grim reality. Table 1 compares three 
contiguous seven year periods - the first seven years of Sweeney's presidency (19952002), the last seven years under his predecessor Lane Kirkland (1988-1995), and the Reagan years (1981-1998). Clearly union density declined most rapidly during the Reagan years, but the results for the Kirkland years after the release of The Changing Situation and the Sweeney years are almost identical.

\section{Insert Table 1 here}

Table 2 looks at comparative trends for the ten industry groups with the most union members (accounting for approximately $90 \%$ of total membership). The story is the same; although the pace of decline has slowed a bit for some industry groups (and even turned around for the hospital industry), contraction has accelerated for others. Even in those industries and occupations where recruitment efforts have been most obvious and where there have been notable major victories, the results are extraordinarily disappointing. Clearly the heightened level of organizing activity has not been sufficient to overcome either the difficult environment for unions in the U.S., or the institutional inertia inherent in the labor movement.

\section{Insert Table 2 here.}

\section{The Future of Organizing ${ }^{2}$}

Strategic discussions in U.S. labor circles about what needs to be done at this juncture to reverse the slide in density start from the premise that recruitment is the key.

\footnotetext{
${ }^{2}$ This section is based in part on presentations at a meeting of the Organizing Research Network held at Harvard University on June 23 and 24, 2003. Especially relevant were the formal comments of Steven Lerner of SEIU, Paul Booth of AFSCME, Phil Kugler of the American Federation of Teachers, Kim Moody of Labor Notes, and Sheldon Friedman of the AFL-CIO. The conclusions reached reflect the author's long term collaborative work with Bill Fletcher, Jr., of the TransAfrica Forum.
} 
The debate revolves around not what else may need attention to promote revitalization, but instead on how to increase the effectiveness of organizing campaigns. One prominent view advises patience, arguing that progress is modest because members and local leaders are still wed to the servicing model. With time and experimentation, the organizing priority will spread more widely and deeply and density will begin to rebound.

The strongest proponents of the Changing to Organize framework concur that the servicing model still prevails, but go on to argue that this is unacceptable. They stress the urgency of the situation and criticize national union officers' lack of deep commitment to recruitment as reflected in an insufficient shift of resources. A related issue is also raised with a call for more attention to training and retaining organizing staff, and especially to redressing the serious shortage of experienced organizers capable of leading campaigns.

Another viewpoint is that in spite of increased activity, not enough unions are using the appropriate organizing tactics. According to this argument unions are not developing momentum because they are using ill advised, partial or outmoded recruitment methods rather than following the comprehensive union building strategy associated with the organizing model. A variation of this critique is that top down approaches to organizing and centralized control of recruitment are failing, largely because they are undemocratic and eschew rank-and-file empowerment.

Having retrenched from its aspirations to exercise strategic leadership in organizing, the AFL-CIO has not engaged openly in the debate about the most effective strategy. It has continued to promote resource reallocation, and has focused much of its attention on the Voice@ Work campaign to amend labor law. John Sweeney has held steadfastly to the position that aggressive organizing is the key to revitalization: "the first 
and foremost challenge for the American union movement [is] helping the tens of millions of workers in this nation who want to form a union to have that chance" (AFLCIO, 2003).

Early in 2003 the SEIU fueled the flames of debate by publishing a position paper calling for dramatic restructuring to consolidate resources and promote expansion. The SEIU framework is presented as an antidote to creeping general unionism. The premise captures the widely shared frustration with the lack of progress: “... despite many victories and reasons for hope within...the broader labor movement in recent years, the strength of... unions in the United States continues to decline." (SEIU, 2003:2). The SEIU argues that simply increasing the pace and scale of recruitment will not be enough, that simply adopting the correct organizing methods will not be enough, that simply being militant will not be enough. The conclusion is that there is a fundamental weakness in the movement's structure that must be addressed. The SEIU explicitly calls for realignment so that there is a smaller number of large unions that are "... industry focused... not general" (SEIU, 2003:21). Such a realignment will enable unions to demonstrate market power, giving non union workers more incentive to join. The paper closes with a call for open debate about how to establish the rules and culture necessary to facilitate restructuring.

The direction proposed by the SEIU offers an intriguing alternative to the creeping malaise that hangs over the U.S. labor movement. The explicit recognition that simply doing more will not be sufficient is clearly on target. Although the shift in resources to organizing may have fallen short of expectations, there is little to show for the obviously much higher level of recruitment activity. And with a political-economic 
environment that is decidedly less friendly to unions than when the shift to an organizing agenda began in earnest, it is hard to see how resources alone will be sufficient to turn the tide.

But does the structural proposal of the SEIU offer any more promise? The Sweeney led AFL-CIO's modest attempt to strengthen the role of the center in organizing was halted unceremoniously by a broad consensus of national union leaders, determined to retain their strategic independence. The much more dramatic reorganization proposed by the SEIU seems to be unrealistic, and in fact has won little support in the other national unions. Furthermore, it is not clear that structural change alone would do anything to invigorate unions, and indeed the administrative complexity of implementing such realignment would draw attention away from strategic challenges.

The AFL-CIO's Voice@Work campaign is no more realistic. What are the chances for favorable labor law reform with union density and influence clearly on the wane? Shifting resources, restructuring and labor law reform all share a common flaw; they are top down solutions that do not confront weaknesses inherent in the labor movement as it exists. None address the critical challenge of redefining the movement so that it appeals to the mass of unrepresented workers. None offer an alternative to pragmatic, job oriented business unionism that is so weakened that it struggles to deliver its narrow promise of improved wages and working conditions.

The organizing model does suggest hope for an activist revival, but there is little evidence that mobilization has created any momentum for growth. It is widely accepted that recruitment campaigns utilizing tactics consistent with the organizing model have the best chance for success. But as the SEIU paper implies, effective recruitment strategy 
without more substantive institutional change will do no more than stir excitement.

External forces will continue to overwhelm individual campaign victories. And though the proponents of union democracy have a valid complaint that top down change does little to motivate the rank-and-file, there is no evidence that union members are any more willing than leaders to promote radical transformation.

The inherent weakness in both the organizing model and the AFL-CIO's Changing to Organize is the implication that mobilization and effective recruitment will be sufficient to stimulate union renewal. Effective organizing devoid of attention to the complexities of organizational change is self-limiting. True transformation requires greatly expanded member education, coordinated efforts to address resistance from staff and elected leaders, balanced attention to representation and organizing, and comprehensive strategic planning (Fletcher and Hurd, 2001). But it also requires a willingness to redefine the role of unions.

Traditional union approaches have not inspired the new workforce, and no level of organizing activity no matter how well conceived can overcome this deficiency. At least in the U.S., the future of labor requires adaptation and experimentation with diverse forms of representation that respond to the concerns of the expanding professional and technical workforce, that address the instability experienced by part-time and contingent workers, and that create a culture that engages low wage service workers most of whom are immigrants, people of color and women.

But radical transformation is unlikely. Paul Booth, organizing director for AFSCME, has composed a thoughtful response to the SEIU restructuring proposal. He points out that the SEIU conceptualization is only one of several approaches stimulated 
by "...frustration that the change to organize movement hasn't yielded an overall gain in union density" (Booth, 2003:1). He argues that no one strategy for growth is likely to generate consensus at this juncture and posits that a variety of strategies may be required to deal with the range of challenges faced by unions in different sectors of the economy. He calls for open dialogue, experimentation and careful assessment of results from implementation of nine separate strategic approaches that he identifies. His point is that experimentation is better than retrenchment, and that organizing is still central to hope for survival (Booth, 2003).

Realistically, the U.S. labor movement can do little more than continue to pursue revitalization on as many fronts as possible. But the failure to date of the organizing model and the organizing priority should be a lesson to leaders and allies of labor movements in other countries who have been impressed by the promise of narrowly conceived revitalization. Organizing alone is not enough in the U.S. and is unlikely to drive labor movement renewal elsewhere. 


\section{Table 1 \\ Relative Change in Union Density by Sector}

\begin{tabular}{|l|c|c|c|}
\cline { 2 - 4 } \multicolumn{1}{c|}{} & $\mathbf{1 9 8 1 - 8 8}$ & $\mathbf{1 9 8 8 - 9 5}$ & $\mathbf{1 9 9 5 - 2 0 0 2}$ \\
\hline Total & -21.5 & -11.3 & -10.7 \\
\hline Private & -32.1 & -18.9 & -16.5 \\
\hline Public & +6.7 & +3.0 & +0.3 \\
\hline
\end{tabular}

Source: Barry T. Hirsch and David Macpherson, Union Membership and Earnings Data Book, 2003 edition, pp. 11, 12, 16. 


\section{Table 2 \\ Relative Change in Union Density by Industry Group}

\begin{tabular}{|l|c|c|}
\hline \multicolumn{2}{l}{$\mathbf{1 9 8 8 - 1 9 9 5}$} & $\mathbf{1 9 9 5 - 2 0 0 2}$ \\
\hline Construction & -13.7 & -0.5 \\
\hline Durable Goods Manufacturing & -20.3 & -17.5 \\
\hline Non-durable Goods Manufacturing & -20.1 & -20.8 \\
\hline Transportation & -11.9 & -10.8 \\
\hline Communication & -23.6 & -23.7 \\
\hline Utilities & -6.4 & -9.3 \\
\hline Retail Trade & -9.1 & -25.0 \\
\hline Hospitals & -5.4 & +1.4 \\
\hline Education & +1.4 & -1.4 \\
\hline Public Administration & +6.0 & +1.6 \\
\hline
\end{tabular}

Sources: Barry T. Hirsch and David Macpherson, Union Membership and Earnings Data Book, 1996 edition, pp. 74-80, 1999 edition, pp. 128-135, 2003 edition, pp. 48-55. 


\section{References}

American Federation of Labor-Congress of Industrial Organizations. 1985. The

Changing Situation of Workers and Their Unions.

--------. 1997. "Program Summary.” February.

---------. 1998. "Program Summary and Budget Proposal." January.

-------. 2001.America@Work. January.

--------. 2002. "FY2002-2003 Program Summary." February.

---------. 2003. "Remarks by AFL-CIO President John Sweeney, Organizing Press Conference," press release, February 26.

Bahr, Morton. 1989. "Mobilizing for the '90s," Labor Research Review, no. 14, 59-65.

Banks, Andy and Jack Metzgar. 1989. "Participating in Management: Union Organizing on a New Terrain," Labor Research Review, no. 14, 1-55.

Bensinger, Richard. 1998. "When We Try More, We Win More: Organizing the New Workforce," in Jo-ann Mort, Not Your Father's Labor Movement, 27-41.

Booth, Paul. 2003. "Nine Theories in Search of Evidence." Presented to the Organizing Research Network, Cambridge, MA, June 23.

Bronfenbrenner, Kate and Rob Hickey. 2004. "Changing to Organize: A National Assessment of Union Strategies," in Ruth Milkman and Kim Voss, Organize or Die: Labor's Prospects in Neoliberal America. Forthcoming.

Bronfenbrenner, Kate, Sheldon Friedman, Richard W. Hurd, Rudolph A. Oswald and Ronald L. Seeber, 1998. Organizing to Win. Cornell University Press, Ithaca, N.Y.

Carter, Bob and Rae Cooper. 2002. "The Organizing Model and the Management of Change: a Comparative Study of Unions in Australia and Britain," Relations Industrielles, vol. 57, no. 4, 712-742.

Conrow, Theresa. 1991. "Contract Servicing From an Organizing Model," Labor Research Review, no. 17, 45-59.

Diamond, Virginia. 1988. Numbers That Count, AFL-CIO. 
Fletcher, Bill, Jr., and Richard Hurd. 1998. "Beyond the Organizing Model: the Transformation Process in Local Unions," in Kate Bronfenbrenner, et.al., Organizing to Win, 37-53.

Fletcher, Bill, Jr., and Richard Hurd. 2000. "Is Organizing Enough? Race, Gender and Union Culture," New Labor Forum, no. 6, 59-69.

Fletcher, Bill, Jr., and Richard Hurd. 2001. "Overcoming Obstacles to Transformation: Challenges on the Way to a New Unionism," in Lowell Turner, et.al., Rekindling the Movement, 182-208.

Foerster, Amy. 2001. "Confronting the Dilemmas of Organizing: Obstacles and Innovations at the AFL-CIO Organizing Institute," in Turner, et. al., Rekindling the Movement, 155-181.

Frazer, Steve. 1998. "Is Democracy Good for Unions," New Labor Forum, no. 3, 74-93.

Gall, Gregor. 2003. Union Organizing: Campaigning for Trade Union Recognition. Routledge, London.

Heery, Edmund. 2001. "Learning from Each Other: a European Perspective on American Labor," Journal of Labor Research, vol. XXII, no. 2, 307-319.

Heery, Edmund, Melanie Simms, Rick Delbridge, John Salmon, and Dave Simpson. 2000. "Union Organizing in Britain: Survey of Policy and Practice," International Journal of Human Resource Mangement, vol. 11, no. 5, 986-1007.

--------. 2003. "Trade Union Recruitment Policy in Britain: Form and Effects," in Gilbert Gall, Union Organzing, 56-78.

Hurd, Richard. 2001. "Contesting the Dinosaur Image - the U.S. Labour Movement's Search for a Future," Transfer: the European Review of Labour and Research, vol. 7 , no. 3, 451-465.

Hurd, Richard, Ruth Milkman and Lowell Turner. 2003. "Reviving the American Labor Movement: Institutions and Mobilization," European Journal of Industrial Relations, vol. 9, no. 1, 99-117.

Labor Research Review. 1986. “Organize,” no. 8.

--------. 1989. "Participating in Management," no. 14.

-------. 1991. “An Organizing Model of Unionism,” no. 17. 
Meyerson, Harold. 1998. "A Second Chance: The New AFL-CIO and the Prospective Revival of American Labor," in Jo-ann Mort, Not Your Father 's Labor Movement, 1-26.

Mort, Jo-Ann. 1998. Not Your Father's Labor Movement. Verso/New Left Books. New York, NY.

Muehlenkamp, Robert. 1991. "Organizing Never Stops," Labor Research Review, no. 17, 1-6.

Northrup, Herbert R. 1990. "The AFL-CIO Blue Cross-Blue Sheild Campaign," Industrial and Labor Relations Review, vol. 43, no. 5, 525-541.

Raynor, Bruce. 1996. Organizing for Change, Changing to Organiz. AFL-CIO.

Service Employees International Union. 2003. "United We Win: A Discussion of the Crisis Facing Workers and the Labor Movement." February.

Sweeney, John J., Richard Trumka, and Linda Chavez Thompson. 1995. "A New Voice for American Workers." June 28.

Turner, Lowell, Harry C. Katz and Richard W. Hurd. 2001. Rekindling the Movement: Labor 's Quest for Relevance in the $21^{\text {st }}$ Century. Cornell University Press, Ithaca 